\title{
Small Talk in English and Armenian
}

\author{
Ani Vanyan \\ Yerevan State University
}

\begin{abstract}
The present article is aimed at presenting an analysis of the pragmatic functions of small talk in the light of general principles of linguistics in order to explore phatic communication (a verbal communication between a speaker and a hearer to maintain social relationship) between the interlocutors in English and Armenian languages. The investigation of the cases under study shows that the functions and ways of expressing small talk have not only gender differences, but also cultural peculiarities. Phatic utterances may also serve as markers of interlocutors' gender, education, age and social status. In general, the use and avoidance of phatic cues in conversations affect the contact and relations between the interlocutors.
\end{abstract}

Key words: small talk, phatic communication, phaticity, "How are you" utterances, conversational move.

\section{Introduction}

Phatic communication is a verbal communication between a speaker and a hearer to maintain the social relationship between them, without emphasising the information content of the communication. The maintenance of the social relationship between the two sides is carried out by breaking the silence, starting a conversation, making small talk, making gossip, keeping talking, expressing solidarity, creating harmony, creating comfort, expressing empathy, expressing friendship, expressing respect and politeness.

The term phatic (from Greek phatos: spoken) originated in the writings of the British functionalist school of linguistics. The first usage of the term is 
considered to be by Bronisław Malinowski in his essay "The Problem of Meaning in Primitive Languages" (1923).

Phatic communication is also known as phatic communion, more commonly as small talk. Since its introduction, small talk has been used as a concept in sociolinguistics, semantics, stylistics, and communication, and usually points out a conventionalized discourse type. "Phaticity" is a multidimensional potential for talk in many social settings, where speakers' relational goals supersede their commitment to factuality and instrumentality" (Coupland, Coupland, Robinson 1992).

\section{A Historical Review}

The phrase "phatic communion" is closely connected with ritualized aspects of social interaction. Malinowski defined phatic communion as "language used in free, aimless, social intercourse" (Malinowski 1923). Recent terms such as "phatic communication" and "phatic speech" emphasize mostly the function of conversations.

Noteworthy is Jakobson's characterization of phatic communion. He points out that phatic communion is part of the communication model he proposes. According to this model, any speech event has six factors and each of these factors is associated with a function of language. The six factors are: the addresser, addressee, message, code, context, contact; and respectively the emotive, conative, poetic, metalingual, referential, and phatic functions of language (Jakobson 1960).

Putting emphasis on the difference of Jakobson's definition to that of Malinowski, Schneider (1988) notes that Malinowski stressed more the creation of ties or the relational goal of phatic messages, while, for Jakobson, phatic utterances help to maintain contact between speakers of a speech event. Abercrombie pointed out that, "the actual sense of the words used in phatic communion matters little" (Abercrombie 1956). Bull and Roger (1982) defined the term phatic as "speech that initiates conversation but that is [...] conventional and ritualised, such as Hello, How are you? etc. Neither approach offers much cross-cultural insight, as the functions of phatic communion are 
highly variable across cultures. It is of great importance to understand how and when a certain conversation can be categorized as phatic or not.

It is of great importance to attempt to discover pragmatic and communicative functions of phatic talk in face-to-face communication. In trying to do so, we will compare the degrees of phaticity found in the responses to the question How are you? among the British and Armenians.

\section{Analyzing Functions of Small Talk}

Though small talk has little useful purpose, it is a very important bonding ritual for managing interpersonal distance. The main pragmatic function is to help establish relationships between friends and new acquaintances. The desired function is often dependent on the point in the conversation at which the small talk occurs.

Small talk can occur at the beginning of a conversation. When the talkers do not know each other well enough, it allows them to show that they have friendly intentions and desire positive interaction. In case of already existing relationship between the two talkers, their small talk serves as an introduction which provides ground for engaging in more functional topics of conversation later. The main pragmatic function here is to signal the speakers' own mood and to sense the mood of the other person.

The following example from Salinger's "A Perfect Day for a Bananafish" (1953) is a good illustration of a small talk at the beginning of a conversation:

"Hey. Hello, Sybil."

"Are you going in the water?"

"I was waiting for you," said the young man. "What's new?"

"What?” said Sybil.

"What's new? What's on the program?"

"My daddy's coming tomorrow on an airplane," Sybil said, kicking sand. 
"Not in my face, baby," the young man said, putting his hand on Sybil's ankle. "Well, it's about time he got here, your daddy. I've been expecting him hourly. Hourly."

(Salinger 1953)

The above mentioned dialogue proves that the speakers do not know each other well. This phatic utterance shows also the difference between the age of the interlocutors.

Small talk can occur at the end of a conversation, as well. Suddenly ending an exchange may risk at rejecting the other person. The pragmatic function of small talk here is to mitigate that rejection, affirm the relationship between the two people, and soften the parting.

Small talk can act as a space filler to avoid silence. In many cultures, silence between two people is usually considered impolite. This tension can be reduced by starting phatic talk until a more factual subject arises.

Small talk may be extensively used in phone calls. There are instances of phone conversations in Salinger's "Nine Stories", which we would like to analyze here. Here are examples from “A perfect Day for Bananafish” (1953) and "Pretty Mouth and Green My Eyes" (1953):

"Hello," she said, keeping the fingers of her left hand outstretched and away from her white silk dressing gown, which was all that she was wearing, except mules - her rings were in the bathroom.

"I have your call to New York now, Mrs. Glass," the operator said.

"Thank you," said the girl, and made room on the night table for the ashtray. (Salinger 1953)

Summing up, we can say that the sub-paradigms of phatic communication are following:

- Communication starters - greetings.

- Communication supporters - pause fillers. 
- Communication terminators - with the main function of establishing a continuing consensus for the future encounters.

\section{Phatic Talk among the British and Armenians}

The fact that How are you? (HAY?) occurs routinely in every person's life, $H A Y$ ? utterances are considered to be central examples of phatic communication.

When asked, How are you? by an acquaintance not known well, a person chooses such a simple, generalised answer as, I am good, thank you. In this case it is not appropriate to reply with a list of symptoms of any medical conditions suffered from. If such a reply is chosen, it means that the two speakers know each other quite well. Otherwise, this may create an uncomfortable situation.

$H A Y$ ? utterances are a class of conversational moves that need not be delimited as to precise forms and functions. As to the criteria we have been discussing, they have a clear phatic potential (Coupland, Coupland, Robinson 1992). Berger and Bradac (1982) noted that how are you? is often not intended to produce self-revelation but rather merely to signal acknowledgement of the other. The authors also commented that literalist interpretations of how are you? are the basis of an old joke:

\section{A: How are you?}

B: I have bursitis; my nose is itching; I worry about my future; and my uncle is wearing a dress these days.

(Berger and Bradac 1982)

From this point of view, we can compare Armenian and British and American answers to How are you? and say that what is a joke for the latter, is quite a natural thing for the former. When asked a simple question how are you? Armenians are likely to tell about latest events, about different symptoms of illnesses, about their neighbour's daughter who married a very rich man, etc. This is especially true for elderly people. 
In order to find responses of native English speakers we have used the data from the article "How are you? Negotiating Phatic Communion" (Coupland, Coupland, Robinson 1992). The corpus in the article is a series of interviews with elderly people (34 women and 6 men) aged 64 to 90 . All were volunteers who attended a Day Centre (social club) in Cardiff, United Kingdom. They were asked to be involved in a survey of experiences of health care, making it clear that the interviewers were not themselves health practitioners or health specialists of any sort. They were asked a series of prepared questions about health care. The first verbal step was a conversational move: How are you? said smiling and without any primary stress.

The research proves that elderly speakers did tend to behave more disclosively than younger adults. This article, therefore, was particularly interested to examine responses elderly people make to $H A Y$ ? utterances.

Only a few uncontroversially phatically oriented responses did emerge:
A: Alright, thank you.
B: Oh, I'm fine thank you.

In order to compare the answers of Armenian elderly people, I conducted my own survey. The same question was asked to the elderly people among my relatives and neighbours, and surprisingly enough, no one gave a positive, phatically oriented answer. They either did not respond at all or gave a negative response.

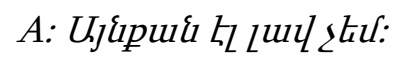

Not so well.)

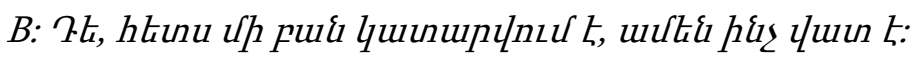

Something is going wrong with me. Everything is out of order.

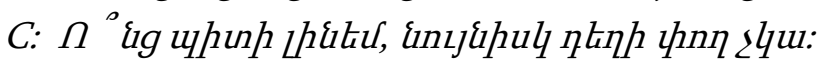

How do I feel? I even do not have money for medicine. 
In many cases the native English speakers used filled pauses (oh; well; erm; etc.) which signal the pragmatic function of self-appraisal.

A: Oh (...) not too bad. (there are five initial oh-s)

B: Well (...) up and down like you know (there are 2 initial well-s)

C: Erm, not too bad.

The same phenomenon was observed in case of our investigation among the Armenians. Moreover, except filled pauses, there were also some utterance post-qualifiers (a local dialect feature).

The not too bad formula is common with the native speakers of both languages:

Responses of English speakers:

A: Not too bad.

B: Well, I'm not so bad.

C: Well, could be better.

D: Not too bad, could be better I suppose.

E: Coming on.

Responses of Armenian speakers:

A: ¿npulu hy, nig qhuntu:

Not bad. Nothing has changed.

B: Euutur hy uliu' ' yuun sh:

Not too bad.

C: Лupp црu:

On feet. (figuratively)

D: Ashirs hh:

So-so.

The above mentioned examples of small talk show how the phrase not too bad has become conventionalised as a $H A Y$ ? response, at least in our own cultural context. 
Another way of mitigating the impact of initial negative appraisals is to give information on specific medical circumstances in the form of justifications.

A: Well not very well, I've just had a bad fall.

B: Well, I'm not feeling very well at all.

C: Not very well, I suffer from awful depression.

Good for my age and as well as can be expected formats are more observed among the interviewees from the United Kingdom than those form Armenia.

A: Fine, well a few aches and pains like everybody else, but still ...

$B:$ Oh, quite good really, um ...

C: Well, I'm alright, I don't grumble, I'm eighty-one.

D: Not too bad, keeping stable.

Another difference observed is the fact that nearly all the responses of elderly people from the UK were made with laughter. Even where it is a negative appraisal, it is again mitigated.

The results of our investigation are represented in the table below.

Figure 1

\begin{tabular}{|l|l|l|}
\hline$\%$ & $\begin{array}{l}\text { English interviewees } \\
(40 \text { people })\end{array}$ & $\begin{array}{l}\text { Armenian interviewees } \\
(40 \text { people })\end{array}$ \\
\hline Negative responses & $25 \%$ & $35 \%$ \\
\hline Positive responses & $10 \%$ & $20 \%$ \\
\hline \multicolumn{1}{|c|}{ not too bad formulas } & $55 \%$ & $45 \%$ \\
\hline $\begin{array}{l}\text { Phatically oriented } \\
\text { responses }\end{array}$ & $10 \%$ & $0 \%$ \\
\hline
\end{tabular}


We have carried out another investigation in an Armenian hospital with different age groups to find out phatic and non-phatic responses. The results are represented in the table below:

Figure 2

\begin{tabular}{|l|l|l|}
\hline$\%$ & $\begin{array}{l}\text { Interviewees aged 15-30 } \\
(20 \text { people })\end{array}$ & $\begin{array}{l}\text { Interviewees aged 30 and more } \\
(20 \text { people })\end{array}$ \\
\hline Phatic & $85 \%$ & $60 \%$ \\
\hline Non-phatic & $15 \%$ & $40 \%$ \\
\hline
\end{tabular}

As evident from the table, there is a great difference between the age groups. Younger people's responses are phatically oriented to a great extent. We observed the following answers to the doctor's question How are you?

A: Luil ku, nnıp hizuku tp:

Fine, and you?

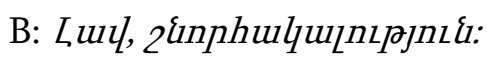

Fine, Thank you.

C: Luน นu... (silence)

Hmmm.

Of course, we can argue that all the responses are phatic. But nearly all of the respondents, irrespective of the observed language, are vivid examples of Malinowski's original concept of phatic communion.

\section{Conclusion}

As it has been shown the rules and topics of phatic communication can differ widely between cultures. The differences are observed even in responses to such a generalized and simple question as How are you? The responses differ in the degree of their phaticity in the observed languages, i.e. English and Armenian. 
As our research proves, the nature of small talk conversations greatly depends on people's age. Younger people tend to give phatically oriented responses, whereas elderly people's responses depend on particular topic or transaction.

\section{References:}

1. Coupland, J.; Coupland, N.; Robinson, J.D. (1992) How are you? Negotiating Phatic Communion. // Language in Society, Vol. 21 (2). Cambridge: CUP.

2. Malinowski, B. (1923) The Problem of Meaning in Primitive Languages. // The Meaning of Meaning. London: Routledge.

3. Goffman, E. (1959) The Presentation of Self in Everyday Life. New York: Doubleday.

4. Salinger, J.D. (1953) Nine Stories. US: Little, Brown and Company.

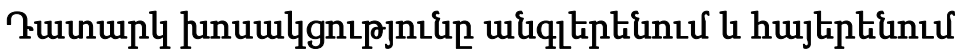

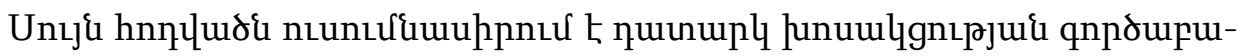

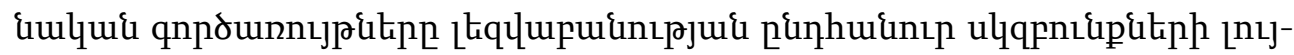

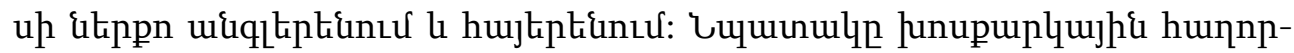

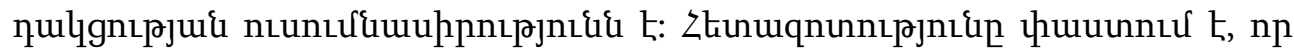

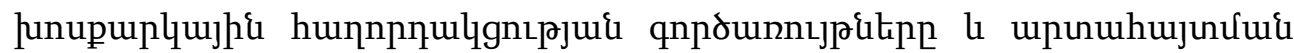

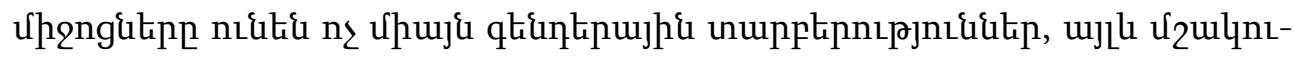

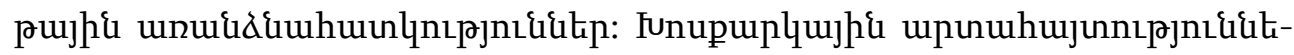

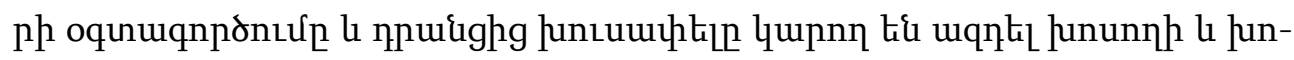
uulgh hupuptennıpjnı\&ukph lnu: 